\title{
A ESPIRAL DE TESLA NO ENSINO E APRENDIZAGEM DA MULTIPLICAÇÃO
}

\section{THE TESLA SPIRAL IN TEACHING AND LEARNING MULTIPLICATION}

\author{
Elaine de Sousa Teodosio ${ }^{1}$
}

Secretaria de Educação do Ceará

\begin{abstract}
Resumo
O presente trabalho apresenta resultados parciais de uma pesquisa de natureza bibliográfica que estuda a Espiral de Tesla ou Mapa da Multiplicação como recurso metodológico no desenvolvimento da prática pedagógica no Ensino Médio, principalmente para os alunos que têm dificuldade com a multiplicação. No texto apresentamos como obtemos os múltiplos. O texto apresenta ainda ideias importantes que justificam a importância da História da Matemática no processo educativo. Além disso, a Espiral de Tesla na formação de professores, como uma estratégia metodológica, pode contribuir efetivamente na re(siginificação) da multiplicação promovendo impactos no processo de ensino e aprendizagem. A História da Matemática motiva e estimula a participação dos alunos no processo educativo, enriquece o desenvolvimento das aulas, esclarece dúvidas e questionamentos, pois apresenta a Matemática como uma criação humana, os discentes percebem que a mesma passou por diversas transformações ao longo do processo histórico, compostas de erros e acertos e, assim é possível desconstruir, em alguns professores e alunos, a visão de que a Matemática é um saber estático, hermético, composto de conhecimentos inquestionáveis e imutáveis.
\end{abstract}

Palavras-chave: História da matemática; Mapa da Multiplicação; Recurso didático.

\section{Abstract}

The present work presents partial results of a bibliographic research that studies Tesla's Spiral or Multiplication Map as a methodological resource in the development of pedagogical practice in High School, mainly for students who have difficulty with multiplication. In the text we present how we obtain the multiples. The text also presents important ideas that justify the importance of the History of Mathematics in the educational process. In addition, the Tesla Spiral in teacher training, as a methodological strategy, can effectively contribute to the re (siginification) of multiplication, promoting impacts on the teaching and learning process. The History of Mathematics motivates and encourages the participation of students in the educational process, enriches the development of classes, clarifies doubts and questions, as it presents Mathematics as a human creation, students realize that it has undergone several transformations throughout the historical process, composed of mistakes and successes and, thus, it is possible to deconstruct, in some teachers and students, the view that

${ }^{1}$ prof.mat.elaineteodosio@gmail.com

Número Especial - IV Seminário Cearense de História da Matemática

Boletim Cearense de Educação e História da Matemática - Volume 07, Número 20, 233 - 240 (2020)

DOI: $10.30938 /$ bocehm.v7i20.2930 
Mathematics is a static, hermetic knowledge, composed of unquestionable and immutable knowledge.

Keywords: History of mathematics; Multiplication Map; Didactic resource.

\section{Introdução}

Atualmente, um dos desafios do ensino consiste no elo que deve ser estabelecido entre o conhecimento compartilhado em sala de aula e o cotidiano dos alunos. Enquanto agente de mudança social, as disciplinas têm que proporcionar o desenvolvimento intelectual, o entendimento de conceitos e procedimentos metodológicos associados a atitudes e valores, promovendo a busca pela compreensão da sociedade e suas transformações. Neste sentido, para que o aluno esteja preparado e passe a relacionar os conhecimentos escolar com suas vivências cotidianas, faz-se necessário investir na formação continuada de professores.

Os nossos alunos do Ensino Médio, uma parcela significativa, apresentam muitas dificuldades na multiplicação e consequentemente na divisão. Portanto concordamos com Cavalcante (2014) que reforça que é de suma importância que no processo de aprendizagem o professor não trabalhe apenas conceitos de forma isolada. Esta característica naturalística do conhecimento pouco acrescentaria no processo de humanização.

Percebemos que, na maioria das vezes, os alunos não percebem a matemática como uma criação humana, com intuito de modificar essa visão e com o objetivo que eles entendam que a Matemática passou por diversas transformações ao longo do processo histórico, compostas de erros e acertos, e, também com o propósito de desconstruir essa visão ainda muito forte de que a mesma é uma verdade absoluta, apresentaremos através História da Matemática, pois a mesma motiva e estimula a participação dos alunos no processo educativo, a espiral de Tesla ou mapa da multiplicação como um recurso pedagógico no processo de ensino e aprendizagem da multiplicação.

\section{Espiral de Tesla}

A História da Matemática pode contribuir para a melhoria das aulas de Matemática e a intersecção dessas duas áreas aplicadas adequadamente pode trazer novos ares à sala de aula e assim professores e alunos produzirão conhecimento e 
consequentemente promoverão a cidadania. De acordo com MIGUEL e MIORIN (2004, p.53):

Dessa forma, podemos entender ser possível buscar na História da Matemática apoio para atingir, com os alunos, objetivos pedagógicos que os levam a perceber por exemplo; (1) a matemática como uma criação humana; (2) as razões pelas quais as pessoas fazem matemática; (3) as necessidades práticas sociais, econômicas e físicas que servem de estimulo ao desenvolvimento das ideias matemáticas; (4) as conexões existentes entre matemática e filosofia, matemática e religião, matemática e lógica, etc.; (5) a curiosidade estritamente intelectual que pode levar à generalização e extensão de ideias e teorias; (6) as percepções que os matemáticos tem do próprio objeto da matemática, as quais mudam e se desenvolvem ao longo do tempo.

Neste contexto, a educação tem uma dimensão mais ampla, possibilitadora da humanização dos homens. Mas para que isso ocorra torna-se imprescindível que o professor prepare suas atividades não apenas para apropriação de conceitos puramente científicos. É necessário que o aluno também se forme culturalmente, tendo acesso a conhecimentos relativos às necessidades de criação dos conceitos estudados, o contexto cultural no qual surgiram, dentre muitas outras variáveis, influenciadas pela cultura e pelo meio social.

De acordo com os Parâmetros Curriculares do Ensino Médio (1998) é importante permitir conexões entre diversos conceitos matemáticos e entre diferentes formas de pensamento matemático, ou, ainda, a relevância cultural do tema, tanto no que diz respeito às suas aplicações dentro ou fora da Matemática, como à sua importância histórica no desenvolvimento da própria ciência.

Fazenda (2007) afirma que, em se tratando de ensino, os currículos das disciplinas tradicionais, da forma como vêm sendo desenvolvidos, oferecem ao aluno apenas um acúmulo de informações pouco ou nada relevantes para a sua vida profissional, pois estão centrados na mera memorização de informações.

Portanto o processo de ensino e aprendizagem deve mobilizar conhecimentos matemáticos, do ponto de vista transdisciplinar que de acordo com Moraes (2015)

\footnotetext{
a transdisciplinaridade, como princípio epistemológico e metodológico, nos incentiva a não permanecermos somente ao nível disciplinar do conhecimento e que, muitas vezes, privilegia os aspectos técnicos, os procedimentos lineares e a externalidade aparente das coisas. Ela enseja o rompimento de barreiras, a superação de fronteiras para poder ir além do conhecimento fruto de uma lógica binária, com seus respectivos valores excludentes, em direção a um conhecer mais profundo, abrangente, integrativo e global.
} 
Dessa forma proporcionamos aos estudantes um contato com outras temáticas, preparando-os para a vida em sociedade, mediando a apreensão do conhecimento, através de uma transposição didática, o documento fica numa linguagem acessível.

Compactuamos com Carvalho (2014), que a atividade de ensino não deve ser tratada simplesmente como uma forma de repassar conhecimento. O professor deve organizá-las de maneira que se origine, no sujeito que aprende (aluno), a necessidade de apropriação de determinados conhecimentos teóricos.

A maior parte dos nossos professores tem uma visão que para ensinar bem precisa-se dominar os conhecimentos específicos/disciplinares. Entendemos, porém, que esses professores, em contanto com os saberes sobre educação e sobre pedagogia, podem encontrar instrumentos para se interrogarem e alimentarem suas práticas, confrontando-os. É aí que se produzem saberes pedagógicos, na ação (PIMENTA, 1997, p.10).

A Espiral de Tesla como estratégia metodológica pode contribuir efetivamente para a melhoria do ensino e da aprendizagem de conteúdos como múltiplos, divisores, sequências numéricas, a formação de compostos, números, primos.

Nikola Tesla, croata, fez diversas contribuições no campo da eletricidade e também em outras áreas como a Espiral que pode ser trabalhada na Teoria dos números com aplicações em outras áreas.

O mapa da multiplicação tem uma configuração visual que auto-organiza todos os números em 12 posições, focaremos os nosso estudos nos os múltiplos, portanto os múltiplos de 2 formam um hexágono não fechado com o crescimento no sentido horário (espiral). Já os múltiplos de 3 formam um quadrado não fechado com o crescimento no sentido horário (espiral), e assim podemos observar os outros múltiplos de acordo com a figura 1 . 


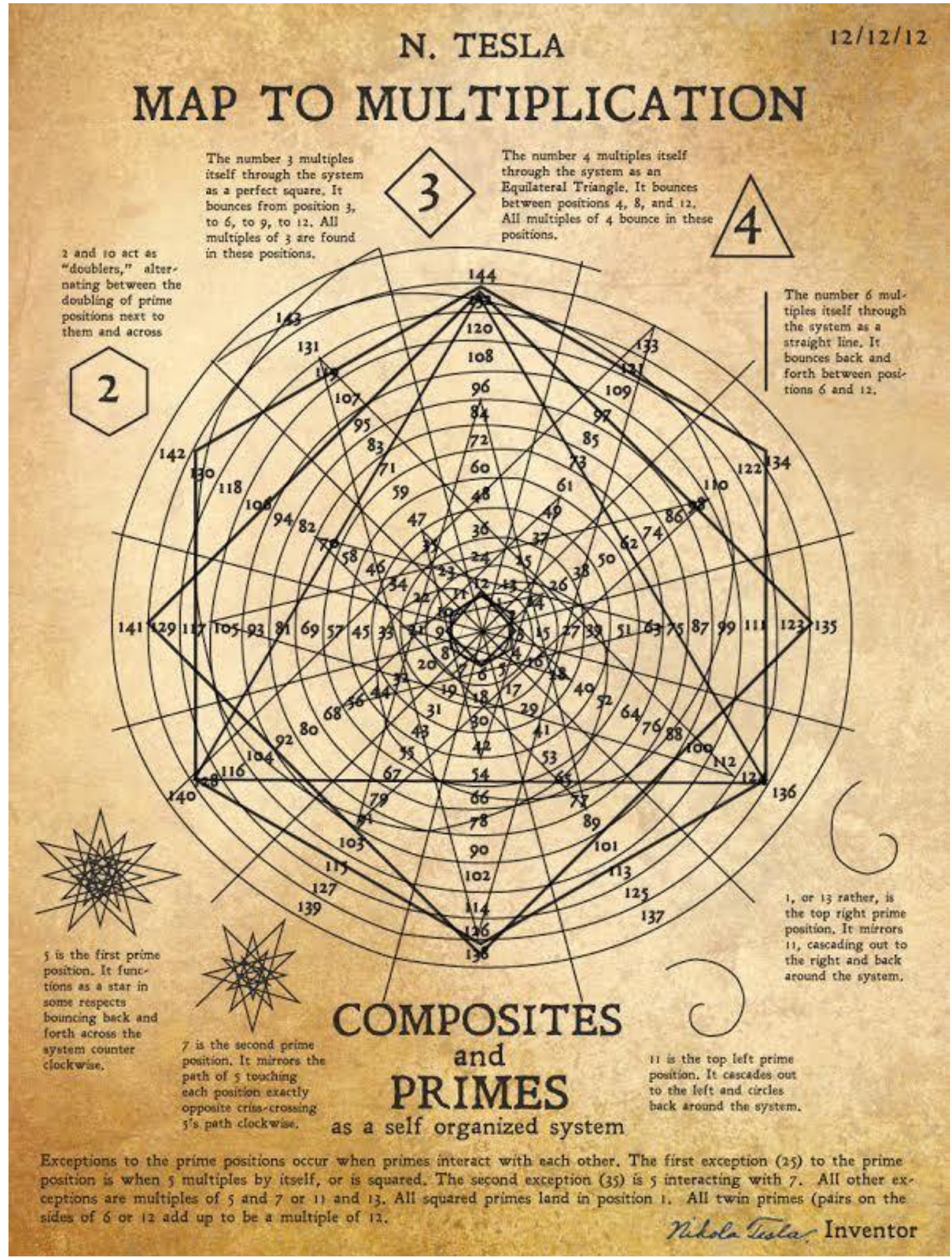

Figura 1 - Espiral de Tesla

Fonte: Tesla

No ensino da multiplicação, o professor que atua no Ensino Médio, poderá fazer uso Espiral de Tesla na sua prática pedagógica com o intuito de estimular a participação ativa do estudante no processo educativo, possibilitando aos mesmos constatar como os saberes da Matemática são evoluções decorrentes de processos 
históricos além disso proporciona aos mesmo um contato com outras temáticas, preparando-os para a vida em sociedade, mediando a apreensão do conhecimento, com uma linguagem acessível.

Dentre os possíveis modos de tratamento de como abordar a história da matemática no ensino nos fundamentamos na lógico-histórica, pois

\begin{abstract}
Os pressupostos do materialismo histórico dialético, em particular a lógica dialética, permitiram-nos um modo de apropriação do conceito tendo como fundamento o seu desenvolvimento lógico-histórico. Consideramos que este é mais amplo que a lógica formal. Enquanto a lógica formal se interessa pela própria forma lingüística de expressão de uma idéia como, por exemplo, de uma definição matemática, a lógica dialética estuda, sobretudo, o conteúdo mental, dando atenção especial à relação desse conteúdo com a realidade objetiva, no próprio processo de pensamento. Liberto das casualidades históricas, o lógico do conceito evidencia o movimento de criação e desenvolvimento deste, na sua essência, pondo a descoberto seus nexos conceituais. (DIAS, 2007, p.10)
\end{abstract}

O desenvolvimento das atividades corrobora com Moura, Araujo e Serrão (2019), no qual, a organização do ensino de matemática, na perspectiva lógico-histórica, significa superar uma perspectiva utilitarista do conceito, marcada, sobretudo, pelo seu aspecto operacional, para considerar o processo humano de criação.

Compactuamos com Carvalho (2014), que a atividade de ensino não deve ser tratada simplesmente como uma forma de repassar conhecimento. O professor deve organizá-las de maneira que se origine, no sujeito que aprende (aluno), a necessidade de apropriação de determinados conhecimentos teóricos.

O mapa da multiplicação pode contribuir para aprendizagem por excelência que de acordo com D’Ambrósio (2012) é a capacidade de explicar, aprender e compreender, de enfrentar criticamente situações novas, e para que isso ocorra o importante não é mudar o arranjo dos móveis na salas, mas sim mudar a atitude do professor porque se não o aprender será um mero domínio de técnicas, de habilidades ou memorização de algumas explicações ou teorias

Diante dos desafios da atual sociedade há a necessidade de uma matemática acessível para um número maior de cidadãos e um ensino que vá além da mecanicidade de decorar fórmulas e algoritmos, portanto, atualmente, é necessário romper com essa tradição tricotômica da formação de professores da Educação Básica que é a formação matemática, a formação didático-pedagógica e a prática profissional (FIORENTINI; OLIVEIRA, 2013). 


\section{Considerações finais}

A aproximação da Matemática com a História da Matemática é uma alternativa para sairmos dessa estruturação de currículo baseada em lista de exercícios, no qual as práticas de ensino estão centradas no professor e, na maioria das vezes, os alunos não se sentem motivados ou desafiados na produção do conhecimento.

Diante disso percebemos que Espiral Tesla estimula a curiosidade do aluno, além disso (re)significa o conceito de multiplicação, e, também proporciona aos mesmos investigar culturas e línguas diferentes, experimentar uma matemática diferente, engenhosa e que pode aguçar o raciocínio matemático.

\section{Referências}

BRASIL. Ministério da Educação. Secretaria de Estado da Educação. Parâmetros Curriculares Nacionais: Matemática. Brasília: MEC/SEF, 1998.

CARVAlHO, D. A EDUCAÇÃo ESTÁ NO GIBI. Campinas: Papirus, 2006.

CAVAlCANTE, L. A. de O. NO DIA MAIS CLARO: um estudo sobre o sentido atribuído às histórias em quadrinhos por professores que ensinam matemática em formação. 2014. 212 f. Dissertação (Mestrado) - Curso de Educação em Ciências e Matemática, Universidade Federal de Goiás, Goiânia, 2014. Acesso em 10/12/2017.

D’AMBROSIO, U. Educação Matemática da teoria à prática. 23 ed. Campinas: Papirus, 2016.

DIAS, M. S. Formação da imagem conceitual da reta: um estudo do desenvolvimento do conceito na perspectiva lógico-histórica. 2007. Tese (Doutoramento em Educação) - Faculdade de Educação, Universidade de São Paulo, 2007

FAZENDA, I. Interdisciplinaridade: um projeto em parceria. 6. ed. São Paulo: Loiola, [1991] 2007.

FIORENTINI, D.; OLIVEIRA, A. T. C. C. O lugar das Matemáticas na Licenciatura em Matemática: que matemáticas e práticas formativas? Bolema, Rio Claro, v.27, n.47, p. 917-938, 2013.

MORAES, M. C. DA ONTOLOGIA E EPISTEMOLOGIA COMPLEXA À METODOLOGIA TRANSDISCIPLINAR. Revista Terceiro Incluído, 2015, Goiânia. Disponível em: https://www.revistas.ufg.br/teri/article/view/36344/18700. 
MOURA, Manoel Oriosvaldo de; ARAUJO, Elaine Sampaio; SERRÃO, Maria Isabel Batista. Atividade Orientadora de Ensino. Linhas Críticas, [s.1.], v. 24, p.411-430, 13 fev. 2019. Biblioteca Central da UNB. http://dx.doi.org/10.26512/lc.v24i0.19817.

MIGUEL, Antônio; MIORIN, Maria A. História na educação matemática: propostas e desafios. Belo Horizonte: Autêntica, 2004.

PIMENTA, S. G. A formação de professores: saberes da docência e identidade. Nuances, Presidente Prudente, v.3, p.5-14, 1997. 